\title{
Environmental Variances of Fruit Traits in a Mandarin-related Population Used in Citrus Breeding in Japan
}

\author{
Hiroko Hamada ${ }^{1}$ and Keisuke Nonaka \\ Citrus Research Division, NARO Institute of Fruit Tree Science, \\ Minamishimabara, Nagasaki 859-2501, Japan
}

Terutaka Yoshioka

Citrus Research Division, NARO Institute of Fruit Tree Science, Shimizu, Shizuoka 424-0292, Japan

\author{
Masahiko Yamada \\ Breeding and Pest Management Division, NARO Institute of Fruit Tree \\ Science, Tsukuba, Ibaraki 305-8605, Japan
}

Additional index words. fruit weight, ease of peeling, firmness of segment membrane, soluble solids content, acidity, yearly repetition, fruit sample size

\begin{abstract}
We estimated environmental variance components for fruit weight (FW), ease of peeling (EP), firmness of segment membrane (FSM), soluble solids content (SSC), and acidity of 20 mandarin and related cultivars used as cross-parents in citrus breeding in Japan. The variance by year was largest for FW (38\% of the total) and SSC (23\%), but negligible for EP, FSM, and acidity. Variance among trees and tree $\times$ year interaction were negligibly small except for $\mathbf{F W}$, whereas the genotype $\times$ year interaction variance ranged from $9 \%$ to $22 \%$ of the total. Variance among fruits from the same tree was the largest environmental component for EP and FSM. Broad-sense heritability $\left(h_{\mathrm{B}}{ }^{2}\right)$ was 0.29 for $\mathrm{FW}, 0.52$ for EP, 0.11 for FSM, 0.34 for SSC, and 0.65 for acidity in evaluations performed using single-year measurements of one tree with one fruit. Yearly repetition was more efficient than tree replication for increasing $h_{\mathrm{B}}{ }^{2}$ of all traits investigated. Increasing fruit number from one to five in combination with yearly repetition also increased $h_{\mathrm{B}}{ }^{2}$, especially for EP and FSM.
\end{abstract}

Satsuma mandarin (Citrus unshiu), the leading citrus crop in Japan, is of Japanese origin and is well adapted to the local climate. It has high productivity, it is disease- and cold-tolerant, and its fruits are easy to eat, being seedless and easy to peel and having soft segment membranes, especially in the early-maturing cultivars. However, the fruits are small and their sugar content is moderate. The consumer demand for Satsuma mandarin has gradually decreased, and current production is only one-fourth of that in 1975 . To maintain and develop the citrus industry in Japan, it is indispensable to develop new mandarin cultivars with large fruits and high sugar content in addition to ease of eating.

The citrus breeding program in Japan began in 1937 at the Horticulture Research Station of the Ministry of Agriculture and Forestry, now the Okitsu Citrus Research Station of the National Agriculture and Food

Received for publication 8 Jan. 2016. Accepted for publication 25 Mar. 2016.

We are indebted to the many people involved in citrus breeding at the NARO Institute of Fruit Tree Science. We sincerely thank them for their efforts. ${ }^{1}$ Corresponding author. E-mail: hirohama@affrc. go.jp.
Research Organization Institute of Fruit Tree Science (NIFTS), and is continuing at the NIFTS Okitsu and Kuchinotsu Citrus Research Stations (Nishiura, 1964). The breeding targets in this program currently focused on fruit traits, such as FW, high SSC, and ease of eating that is determined mainly by EP and FSM. In addition, it is important to broaden the range of maturation time to obtain cultivars adapted to a wide range of growing seasons; the availability of such cultivars would improve profitability and allow optimization of labor allocation. Acidity, which decreases as fruit matures, is one of the main factors that determine fruit maturing time in citrus. These fruit traits would fluctuate owing to environmental (nongenetic) factors such as year, tree, and fruits. Therefore, it is important for fruit tree breeder to distinguish genetic variance from environmental ones. Increasing year repetition, tree replication, and fruit sample size increase the accuracy of genetic differences, but it restricts number of genotypes in a given period and space and reduces the chance of obtaining desirable genotypes in a breeding program.

Analysis of variance (ANOVA) has been used to estimate the contributions of genetic and environmental variance components for fruit traits of Japanese persimmon (Yamada et al., 1993, 2002), grape (Sato et al., 2000), Japanese pear (Machida and Kozaki, 1975, 1976; Nishio et al., 2011), chestnut (Nishio et al., 2014) and for carotenoid contents of citrus (Nonaka et al., 2012). These estimates provide information on optimal yearly repetition, tree or vine replication, and fruit sample size. Estimates of $h_{\mathrm{B}}{ }^{2}$ of traits, which is the ratio of genetic variance to phenotypic variance, are also important for breeders to judge whether a trait could be effectively selected in a breeding program. However, in the citrus breeding program at NIFTS, the availability of such estimates for commercially important fruit traits is limited. Therefore, the objective of the present study was to obtain accurate estimates of the environmental variance components for commercially important fruit traits (FW, EP, FSM, SSC, and acidity) in December, the main season for fruit evaluation in breeding program in Japan, using 20 mandarin and related cultivars that are used as cross-parents in citrus breeding at the Kuchinotsu Citrus Research Station.

\section{Materials and Methods}

Measurement and evaluation of fruit traits. Twenty cultivars (genotypes) used in the study (Table 1) were grown at the NIFTS Kuchinotsu Citrus Research Station in Nagasaki, Japan $\left(32^{\circ} 59^{\prime} \mathrm{N}, 130^{\circ} 18^{\prime} \mathrm{E}\right)$. The age of the trees ranged from 6 to 18 years in 2012, top grafted on C. unshiu that had been grafted on trifoliate orange. The trees were grown using normal cultivation techniques used in commercial production in Japan. Two trees per cultivar were repeatedly measured and evaluated in 2012 and 2013. Five fruits were randomly sampled from each tree in mid-December, and we evaluated FW, EP, FSM, SSC, and acidity. FW was measured on an electronic digital scale (CP8201; Sartorius, Gottingen, Germany). EP was evaluated by peeling fruits by hand and rated on a 1 to 5 scale by one person, where $1=$ fingers can penetrate the rind of fruit apex where the peeling is started with little pressure and can peel it without tearing it off; 3 = fingers can penetrate the rind but cannot peel it without tearing it off; $5=$ fingers cannot penetrate the rind; and 2 and 4 are intermediates.

Fruits were cut in half at the equator line, and segments were evaluated in an eating test. FSM was rated on a 1 to 5 scale by one person, where $1=$ so soft that the membrane cannot be detected during eating; $3=$ the membrane can be detected but can be swallowed easily; $5=$ so hard that the membrane cannot be swallowed; and 2 and 4 are intermediates.

Squeezed juice was used to measure SSC and acidity with an acid and sugar concentration analyzer (NH-2000; Horiba, Kyoto, Japan). Average values of each were positively correlated with SD of FW and acidity; therefore, values of FW and acidity were log 
Table 1. Mandarin and related cultivars and their origins. ${ }^{2}$

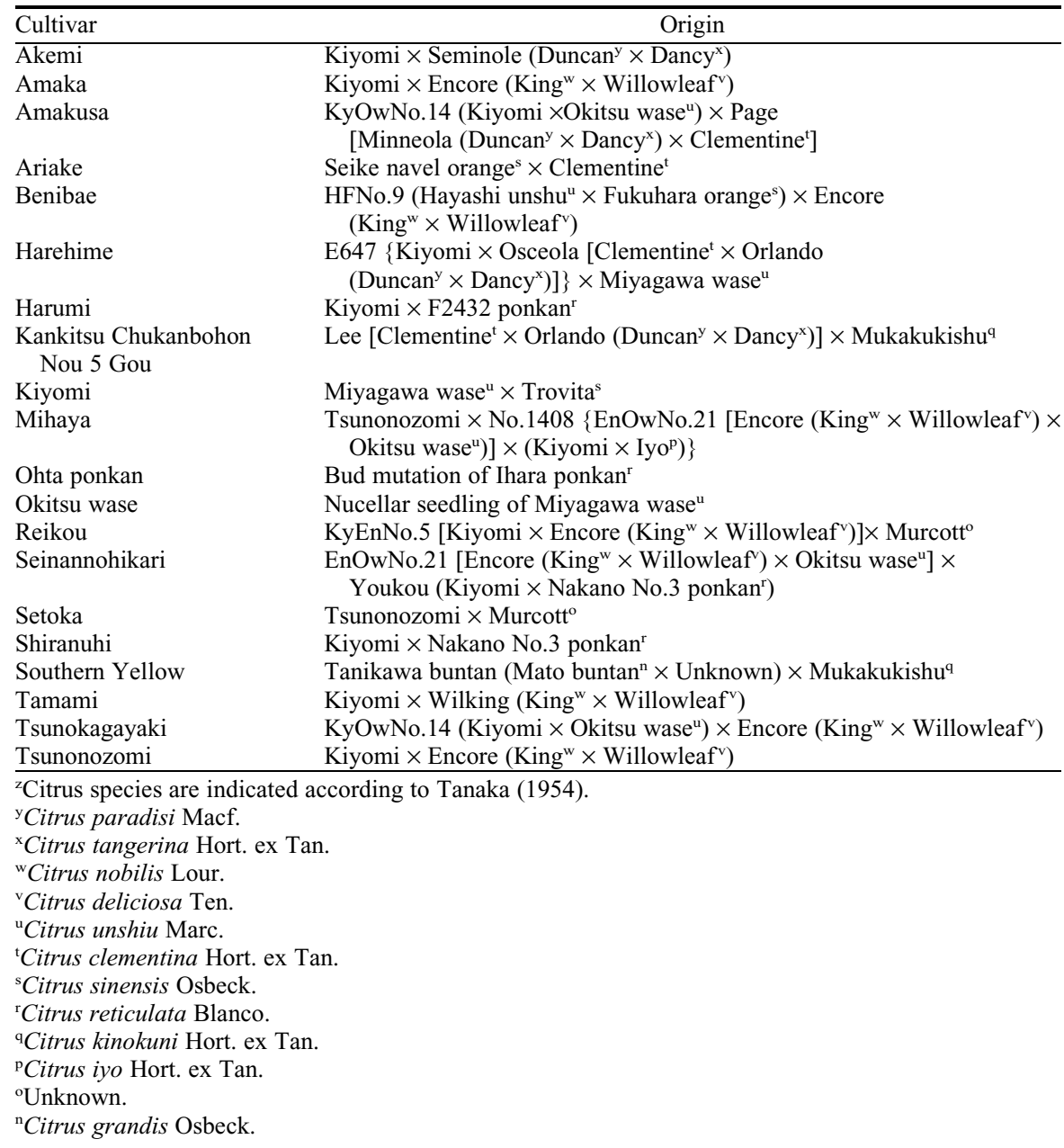

transformed for ANOVA to improve the normality of the distribution of the residual estimates.

Statistical analysis. The value for each fruit was tested by ANOVA with the following model:

$$
\begin{aligned}
P_{i j k l}= & \mu+G_{i}+T_{i j}+Y_{k} \\
& +\mathrm{GY}_{i k}+\mathrm{TY}_{i j k}+E_{i j k l}
\end{aligned}
$$

where $P_{i j k l}$ is the phenotypic value of the $l$ th fruit of the $j$ th tree of the $i$ th genotype in the $k$ th year; $\mu$, the overall mean; $G_{i}$, the effect of the $i$ th genotype; $T_{i j}$, the effect of the $j$ th tree of the $i$ th genotype; $Y_{k}$, the effect of the $k$ th year; $\mathrm{GY}_{i k}$, interaction between the $i$ th genotype and the $k$ th year; $\mathrm{TY}_{i j k}$, interaction between the $j$ th tree of the $i$ th genotype and the $k$ th year; and $E_{i j k l}$, the residual of the $l$ th fruit of the $j$ th tree of the $i$ th genotype in the $k$ th year. In this model, all effects were considered to be random effects. ANOVA provided estimates of variance, associated with genotype $\left(\sigma_{\mathrm{g}}{ }^{2}\right)$, trees within genotype $\left(\sigma_{t}^{2}\right)$, year $\left(\sigma_{y}^{2}\right)$, genotype $\times$ year interaction $\left(\sigma_{\mathrm{gy}}{ }^{2}\right)$, tree $\times$ year interaction $\left(\sigma_{\mathrm{ty}}{ }^{2}\right)$, and fruits within tree $\left(\sigma_{\mathrm{f}}^{2}\right)$.

The distribution of the residuals in the ANOVA model approached normal for all traits, with no significance at $P=0.05$ in the Kolmogorov-Smirnov one-sample test.
The total environmental variance $\left(\sigma_{\mathrm{E}}^{2}\right)$ was calculated as:

$$
\sigma_{\mathrm{E}}^{2}=\frac{\sigma_{\mathrm{y}}^{2}}{y}+\frac{\sigma_{\mathrm{gy}}^{2}}{y}+\frac{\sigma_{\mathrm{t}}^{2}}{t}+\frac{\sigma_{\mathrm{ty}}^{2}}{\mathrm{ty}}+\frac{\sigma_{\mathrm{f}}^{2}}{\mathrm{tyf}}
$$

where $t$ is the number of tree replications per genotype, $y$ is the number of yearly repetition, and $f$ is the number of fruits per tree. We defined $h_{\mathrm{B}}{ }^{2}$ as:

$$
h_{\mathrm{B}}^{2}=\frac{\sigma_{\mathrm{g}}^{2}}{\left(\sigma_{\mathrm{g}}^{2}+\sigma_{\mathrm{E}}^{2}\right)}
$$

\section{Results and Discussion}

Means of the population were $197.8 \mathrm{~g}$ for FW, 2.3 for EP, 1.9 for FSM, 11.2\% for SSC, and $1.2 \mathrm{~g} / 100 \mathrm{~mL}$ for acidity. Means of the genotypes for both years ranged from 115 to $287 \mathrm{~g}$ for $\mathrm{FW}, 1.1$ to 4.1 for EP, 1.3 to 2.6 for FSM, $9.4 \%$ to $13.2 \%$ for SSC, and 0.6 to $2.1 \mathrm{~g} / 100 \mathrm{~mL}$ for acidity.

In ANOVA, the effect of genotype was highly significant ( $P \leq 0.01$ except for FSM), and the effect of genotype $\times$ year interaction was also highly significant $(P \leq 0.01$ except for FW) (Table 2). The effect of year was highly significant $(P \leq 0.01)$ for FW and SSC. The effect of tree within genotype was significant $(P \leq 0.05)$ for EP and acidity, and the effect of the tree $\times$ year interaction was highly significant $(P \leq 0.01)$ for $\mathrm{FW}$, SSC, and acidity.

The contribution of the environmental variance components to the total variance varied with the traits (Table 3 ). The contribution of genetic variance $\left(\sigma_{\mathrm{g}}{ }^{2}\right)$ was the largest $(65 \%)$ for acidity among the five traits, indicating that it would be easy to accurately estimate genetic differences for this trait. On the other hand, $\sigma_{\mathrm{g}}{ }^{2}$ values were small for FW (29\%) and for FSM (11\%), indicating that it would be difficult to estimate genetic differences for these traits. As for FSM, the small value of $\sigma_{\mathrm{g}}{ }^{2}$ could also result from the small difference among genotypes (from 1.3 to 2.6 in the mean) used in the study. On the other hand, $\sigma_{\mathrm{g}}{ }^{2}$ values were the largest $(65 \%)$ for acidity among the five traits, indicating that this genetic trait would have wide range among genotypes and would be distinguished with less fluctuation by environmental factors. The contribution of variance by year $\left(\sigma_{\mathrm{y}}^{2}\right)$ was large for $\mathrm{FW}$ (38\%), but negligibly small for EP, FSM, and acidity. The contribution of the genotype $\times$ year interaction $\left(\sigma_{\mathrm{gy}}{ }^{2}\right)$ ranged from $9 \%$ to $22 \%$ of the total variance; the $\sigma_{\mathrm{gy}}{ }^{2}$ values were largest $(>20 \%)$ for FSM and SSC. The large $\sigma_{\mathrm{y}}{ }^{2}$ and small $\sigma_{\mathrm{gy}}{ }^{2}$ suggest that $\mathrm{FW}$ would be affected by the year similarly in different genotypes, i.e., there would be years with large fruits and years with small fruits, which could be caused by biennial bearing in on and off years. On the other hand, the large $\sigma_{\text {gy }}{ }^{2}$ and small $\sigma_{\mathrm{y}}{ }^{2}$ suggest that FSM would be affected by the year differently in different genotypes, i.e., FSM of some genotypes would be lower and that of the others would be higher than the average of genotypes on the same year. The variances by tree $\left(\sigma_{t}^{2}\right.$ and $\left.\sigma_{\text {ty }}{ }^{2}\right)$ were small except for FW $\left(\sigma_{\text {ty }}{ }^{2}=14 \%\right)$. These results suggest that increasing the number of trees is not effective to increase the accuracy of the genetic properties. The contribution of the fruits within tree $\left(\sigma_{\mathrm{f}}^{2}\right)$ was the largest among environmental variance components for EP and especially for FSM (61\%), indicating that EP and FSM would vary considerably among fruits from the same tree, probably caused by differences in fruit development, maturation, and location within a tree. In addition, as sensory evaluations for these traits were subjective, it would also vary among evaluators though no consideration in this study. Therefore, the variance caused by the evaluators should be examined in future studies.

To assess how yearly repetition, tree replication, and fruit sample size affect the efficiency of the evaluation of these fruit traits, we calculated the $h_{\mathrm{B}}{ }^{2}$ of each traits (Fig. 1). In the case of one tree with one fruit per tree and single-year measurements, $h_{\mathrm{B}}{ }^{2}$ was highest for acidity and lowest for FSM. Increasing the number of fruits on a single tree to five with single-year measurements increased $h_{\mathrm{B}}^{2}$ from 0.29 to 0.32 for FW, 0.52 to 0.69 for EP, 0.11 to 0.23 for FSM, 0.34 to 0.38 for SSC, and 0.65 to 0.71 for acidity. Further increasing the number of fruits on a single tree to 10 with single-year measurements resulted in only 


\begin{tabular}{|c|c|c|c|c|c|c|c|}
\hline \multirow[b]{2}{*}{ Source of variation } & \multirow[b]{2}{*}{$\mathrm{df}$} & \multicolumn{5}{|c|}{ Fruit trait (mean squares) } & \multirow[b]{2}{*}{ Expected mean squares } \\
\hline & & Fruit $w^{z}{ }^{2}$ & Ease of peeling & $\begin{array}{c}\text { Firmness of } \\
\text { segment membrane }\end{array}$ & Soluble solids content & Acidity $^{z}$ & \\
\hline Genotype & 19 & $0.193^{* *}$ & $18.739^{* *}$ & $3.301 \mathrm{NS}$ & $18.542^{* *}$ & $0.407^{* *}$ & 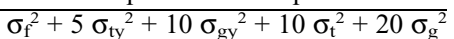 \\
\hline Year & 1 & $2.177 * *$ & $6.502 \mathrm{NS}$ & $0.123 \mathrm{NS}$ & $98.307^{* *}$ & $0.095 \mathrm{NS}$ & $\sigma_{\mathrm{f}}^{2}+5 \sigma_{\mathrm{ty}}^{2}+10 \sigma_{\mathrm{gy}}{ }^{2}+200 \sigma_{\mathrm{y}}^{2}$ \\
\hline Trees within genotype & 20 & $0.008 \mathrm{NS}$ & $0.653 *$ & $0.643 \mathrm{NS}$ & $0.854 \mathrm{NS}$ & $0.022 *$ & $\sigma_{\mathrm{f}}^{2}+5 \sigma_{\mathrm{ty}}{ }^{2}+10 \sigma_{\mathrm{t}}^{2}$ \\
\hline Tree $\times$ year & 20 & $0.022 * *$ & $0.233 \mathrm{NS}$ & $0.343 \mathrm{NS}$ & $1.040^{* *}$ & $0.010^{* *}$ & $\sigma_{\mathrm{f}}^{2}+5 \sigma_{\mathrm{ty}}^{2}$ \\
\hline Fruits within tree & 320 & 0.003 & 0.488 & 0.364 & 0.307 & 0.003 & $\sigma_{f}^{2}$ \\
\hline
\end{tabular}

zData were logarithmically transformed.

Ns, ${ }^{*},{ }^{* *}$ Nonsignificant or significant at $P \leq 0.05$ or $\leq 0.01$, respectively, in F tests.

Table 3. Estimates of variance components and their contributions to the total variance obtained by analysis of variance of fruit traits using 20 genotypes (two trees per genotype) for 2 years.

\begin{tabular}{|c|c|c|c|c|c|}
\hline \multirow[b]{2}{*}{ Variance component } & \multicolumn{5}{|c|}{ Fruit trait (estimate of variance components) } \\
\hline & $\overline{\text { Fruit } \mathrm{wt}^{\mathrm{z}}\left(\times 10^{-2}\right)}$ & Ease of peeling & Firmness of segment membrane & Soluble solids content & $\operatorname{Acidity}^{\mathrm{z}}\left(\times 10^{-3}\right)$ \\
\hline$\sigma_{y}^{2}$ & $1.065(38.4)$ & $0.022(1.4)$ & $0^{\mathrm{x}}(0.0)$ & $0.465(23.1)$ & $0.241(0.9)$ \\
\hline$\sigma_{\mathrm{ty}}{ }^{2}$ & $0.378(13.6)$ & $0^{\mathrm{x}}(0.0)$ & $0^{\mathrm{x}}(0.0)$ & $0.147(7.3)$ & $1.340(5.0)$ \\
\hline$\sigma_{f}^{2}$ & $0.286(10.3)$ & $0.488(31.4)$ & $0.364(61.4)$ & $0.307(15.3)$ & $3.056(11.3)$ \\
\hline
\end{tabular}

${ }^{\mathrm{z}}$ Data were logarithmically transformed.

${ }^{\mathrm{y}}$ Numbers in parentheses show the percentage of each component in the total variance.

${ }^{\mathrm{x}}$ Negative values were assumed to be zero.

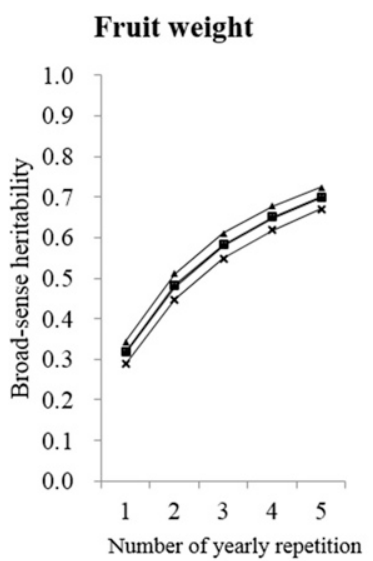

Soluble solids content

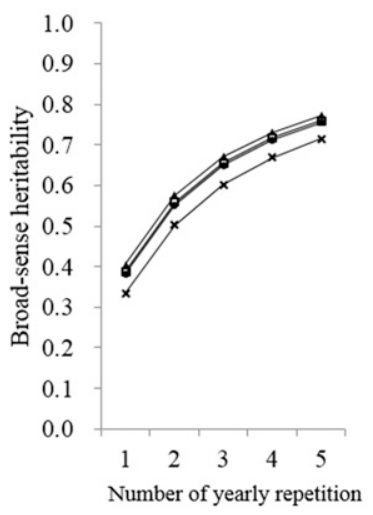

Fig. 1. Effects of the number of fruits per tree, tree replication, and yearly repetition on the broad-sense heritability $\left(h_{\mathrm{B}}{ }^{2}\right)$ of fruit weight, ease of peeling, firmness of segment membrane, soluble solids content, and acidity (see Eq. [3] for $h_{\mathrm{B}}{ }^{2}$ definition). $\times=1$ tree and 1 fruit; $\bullet=1$ tree and 5 fruits; $\square=1$ tree and 10 fruits; $\boldsymbol{\Lambda}=2$ trees and 5 fruits per tree.

small or no increase in $h_{\mathrm{B}}^{2}$ : no change for FW and an increase from 0.69 to 0.72 for $\mathrm{EP}, 0.23$ to 0.26 for FSM, 0.38 to 0.39 for SSC, and 0.71 to 0.72 for acidity. These results suggest that increasing fruit number per tree from one to five was more effective in improving the accuracy for EP and FSM than for FW, SSC, and acidity, but the effect of increasing fruit number per tree from five to ten was small for all traits.
Increasing the number of trees per genotype to two with five fruits per tree and single-year measurement increased $h_{\mathrm{B}}^{2}$ from 0.32 to 0.34 for $\mathrm{FW}, 0.69$ to 0.74 for $\mathrm{EP}, 0.23$ to 0.27 for FSM, 0.38 to 0.41 for SSC, and 0.71 to 0.76 for acidity. Increasing yearly repetition to two with five fruits per tree on a single tree increased $h_{\mathrm{B}}{ }^{2}$ from 0.32 to 0.48 for $\mathrm{FW}, 0.69$ to 0.80 for $\mathrm{EP}, 0.23$ to 0.34 for FSM, 0.55 to 0.81 for SSC, and 0.71 to 0.81 for acidity. In tree replication, $h_{\mathrm{B}}{ }^{2}$ increased because of a decrease in environmental variance associated with $\sigma_{\mathrm{t}}{ }^{2}$ and $\sigma_{\mathrm{ty}}{ }^{2}$, which were smaller than $\sigma_{\mathrm{f}}^{2}$ and $\sigma_{\mathrm{gy}}{ }^{2}$ for each fruit trait except for $\mathrm{FW}$, indicating that tree replication would increase $h_{\mathrm{B}}^{2}$ only slightly. In yearly repetition, $h_{\mathrm{B}}{ }^{2}$ increased because of a decrease in environmental variance associated with $\sigma_{\mathrm{y}}{ }^{2}$, which was the largest environmental variance component for FW and SSC, in addition to decreases in $\sigma_{\mathrm{gy}}{ }^{2}, \sigma_{\mathrm{ty}}{ }^{2}$, and $\sigma_{\mathrm{f}}{ }^{2}$, indicating that yearly repetition would increase $h_{\mathrm{B}}{ }^{2}$, especially for $\mathrm{FW}$ and SSC. Therefore, for the five fruit traits investigated in this study, yearly repetition increased $h_{\mathrm{B}}{ }^{2}$ more efficiently than tree replication did. Increasing the fruit number per tree decreased the environmental variance associated with $\sigma_{\mathrm{f}}^{2}$, whereas yearly repetition decreased the environmental variance associated with not only $\sigma_{\mathrm{f}}^{2}$, but also $\sigma_{\mathrm{gy}}{ }^{2}$, which was the second largest environmental variance component for EP (13\%) and for FSM $(22 \%)$. The efficiency of five fruits per tree per year with 2-year repetition in decreasing $\sigma_{\mathrm{E}}^{2}$ was higher than that of 10 fruits per tree per year with single-year measurements, because the former decreased the environmental variance associated with $\sigma_{\mathrm{y}}{ }^{2}, \sigma_{\mathrm{gy}}{ }^{2}$, and $\sigma_{\text {ty }}{ }^{2}$ in addition to $\sigma_{\mathrm{f}}^{2}$ (i.e., $\sigma_{\mathrm{E}}^{2}=\sigma_{\mathrm{t}}{ }^{2}+\sigma_{\mathrm{y}}{ }^{2} / 2+$ $\left.\sigma_{\mathrm{gy}}{ }^{2} / 2+\sigma_{\mathrm{ty}}{ }^{2} / 2+\sigma_{\mathrm{f}}{ }^{2} / 10\right)$, whereas the latter decreased only variance associated with $\sigma_{\mathrm{f}}^{2}$ (i.e., $\sigma_{\mathrm{E}}^{2}=\sigma_{\mathrm{t}}^{2}+\sigma_{\mathrm{y}}{ }^{2}+{\sigma_{\mathrm{gy}}}^{2}+\sigma_{\mathrm{ty}}{ }^{2}+\sigma_{\mathrm{f}}^{2} / 10$ ). Therefore, increasing both the number of fruits 
and yearly repetition reduced $\sigma_{\mathrm{E}}{ }^{2}$ and increased $h_{\mathrm{B}}^{2}$ more efficiently than increasing only the number of fruits for EP and FSM, which have large $\sigma_{\mathrm{f}}^{2}$ and $\sigma_{\mathrm{gy}}{ }^{2}$.

These results are in line with those of the studies of FW and SSC of Japanese pear (Machida and Kozaki, 1975), Japanese persimmon (Yamada et al., 1993), and grape (Sato et al., 2000). Increasing yearly repetition is more reasonable than increasing the number of tree replications if both increase $h_{\mathrm{B}}^{2}$ similarly, because the latter requires more space and effort (Nishio et al., 2014). Variance by year could be decreased not only by yearly repetition as above, but also by a yearly adjustment procedure using the mean performance of the control genotype over several years (Yamada et al., 1994). However, the efficiency of this adjustment and the optimum number of control genotypes, which depend on the difference between the variance before and after the adjustment, have not been studied for fruit traits in citrus and therefore should be examined in further studies.

The overall citrus genetic resources including pummelo or grapefruit, which are partially used for crossbreeding, likely have larger genetic variance than population of mandarin and related cultivars because the citrus gene pool as a whole has a wider range of fruit traits. In addition, the population used in the study were grown using normal commercial practices, at much lower densities than the populations of cross-bred seedlings in the NIFTS breeding program. Therefore, whether our results could be applied to populations of cross-bred seedlings should be examined in future studies.

Our estimates of environmental variance components are useful not only for evaluation of the relative efficiency of yearly repetition, tree replication, and fruit sample size, but also for genomics-based breeding approaches, including quantitative trait locus (QTL) analyses, genome-wide association studies, and genomic selection, which need accurate phenotype evaluation to build an accurate phenotype database. The effectiveness of molecular markers associated with detected QTLs should be determined as the percentage of explained genetic variance instead of phenotypic variance, because the fluctuation of phenotypic values as a result of environmental variation confounds marker effects (Nishio et al., 2011). Although some molecular markers associated with QTLs for fruit traits of citrus have been reported (Gulsen et al., 2011; Sahin-Cevik and Moore, 2012; Sugiyama et al., 2011), these reports show the contribution of these markers only to phenotypic values, not to genetic variance. Therefore, the estimation of environmental variances for commercially important fruit traits such as FW, EP, FSM, SSC, and acidity could facilitate not only citrus phenotypic selection but also genomic-based breeding.

\section{Literature Cited}

Gulsen, O., A. Uzun, U. Seday, and G. Kafa. 2011. QTL analysis and regression model for estimating fruit setting in young citrus trees based on molecular markers. Sci. Hort. 130:418-424.

Machida, Y. and I. Kozaki. 1975. Quantitative studies on the fruit quality for Japanese pear (Pyrus serotina Rehder) breeding. I. Statistical analyses of cultivar populations. J. Jpn. Soc. Hort. Sci. 44:235-240.

Machida, Y. and I. Kozaki. 1976. Quantitative studies on the fruit quality for Japanese pear (Pyrus serotina Rehder) breeding. II. Statistical analyses of a hybrid seedling population. J. Jpn. Soc. Hort. Sci. 44:325-329.

Nishio, S., M. Yamada, Y. Sawamura, N. Takada, and T. Saito. 2011. Environmental variance components of fruit ripening date as used in both phenotypic and marker-assisted selection in
Japanese pear breeding. HortScience 46:15401544.

Nishio, S., M. Yamada, N. Takada, H. Kato, N. Onoue, Y. Sawamura, and T. Saito. 2014. Environmental variance and broad-sense heritability of nut traits in Japanese chestnut breeding. HortScience 49:696-700.

Nishiura, M. 1964. Citrus breeding and bud selection in Japan. Proc. Fla. State Hort. Sci. 77:79-83.

Nonaka, K., M. Kita, Y. Ikoma, H. Fukamachi, A. Imai, T. Yoshioka, and M. Yamada. 2012. Genetic differences and environmental variations in carotenoid concentrations of fruit flesh in parental population used in citrus breeding in Japan. J. Amer. Soc. Hort. Sci. 137:243-249.

Sahin-Cevik, M. and G.A. Moore. 2012. Quantitative trait loci analysis of morphological traits in citrus. Plant Biotechnol. Rpt. 6:47-57.

Sato, A., M. Yamada, H. Iwanami, and N. Hirakawa. 2000. Optimal spatial and temporal measurement repetition for reducing environmental variation of berry traits in grape breeding. Sci. Hort. 85:75-83.

Sugiyama, A., M. Omura, H. Matsumoto, T. Shimada, H. Fujii, T. Endo, T. Shimizu, H. Nesumi, and Y. Ikoma. 2011. Quantitative trait loci (QTL) analysis of carotenoids content in citrus fruit. J. Jpn. Soc. Hort. Sci. 80:136-144.

Tanaka, T. 1954. Species problem in citrus (revise auranti acearum IX). Jpn. Soc. Promotion Sci., Tokyo, Japan.

Yamada, M., A. Sato, and Y. Ukai. 2002. Genetic differences and environmental variations in calyx-end fruit cracking among Japanese persimmon cultivars and selections. HortScience 37:164-167.

Yamada, M., H. Yamane, and Y. Ukai. 1994. Efficiency of use of control genotype for reducing yearly fluctuations of quantitative fruit characters in Japanese persimmon breeding. Bull. Fruit Tree Res. Sta. 26:29-37.

Yamada, M., H. Yamane, K. Yoshinaga, and Y. Ukai. 1993. Optimal temporal and spatial measurement repetition for selection in Japanese persimmon breeding. HortScience 28: 838-841. 